\title{
Configurações
}

Revista Ciências Sociais

27 | 2021

Vária

\section{Review of: Alipio de Sousa (2019), Revoke Ideology - Critical Constructionist Theory in the Human Sciences, Bern, Switzerland, Peter Lang UK.}

\section{Augusto Francisco}

\section{(2) OpenEdition \\ Journals \\ Edição electrónica \\ URL: https://journals.openedition.org/configuracoes/12179 \\ DOI: 10.4000/configuracoes. 12179 \\ ISSN: 2182-7419 \\ Editora \\ Centro de Investigação em Ciências Sociais}

\section{Edição impressa}

Paginação: 117-121

ISSN: 1646-5075

\section{Refêrencia eletrónica}

Augusto Francisco, «Review of: Alipio de Sousa (2019), Revoke Ideology - Critical Constructionist Theory in the Human Sciences, Bern, Switzerland, Peter Lang UK.», Configurações [Online], 27 | 2021 posto online no dia 02 julho 2021, consultado o 04 julho 2021. URL: http://journals.openedition.org/ configuracoes/12179; DOI: https://doi.org/10.4000/configuracoes.12179 
Francisco, Augusto - Review of: Alipio de Sousa (2019), Revoke Ideology - Critical Constructionist Theory in the Human Sciences, Bern, Switzerland, Peter Lang UK . Configurações, vol. 27, 2021, pp. 117-121.

\section{Review of: Alipio de Sousa (2019), Revoke Ideology - Critical Constructionist Theory in the Human Sciences, Bern, Switzerland, Peter Lang UK}

AUGUSTO FRANCISCO*

Technische Universität Dresden

In Revoke Ideology, Alipio De Sousa aims to explain the critical constructionist theory to a broad audience. To achieve this objective, he reviews many of the key concepts of human sciences facilitating the comprehension and accessibility of the concepts that shape his ultimate proposal. Basically, his sources are, among others, Émile Durkheim, Lévi-Strauss, Louis Althusser, Pierre Bourdieu, Michel Maffesoli, Cornelius Castoriadis, Sigmund Freud, Jacques Lacan, Michel Foucault. This work, then, serves as a reference for professionals and students of human sciences, as well as lay people. The foremost effect of the book's content is to inspire an attitude towards ideology: to revoke it. Although it has political implications, the book is not political partisanship, it is based on rigorous academic research.

With the title of the book proposing the revoking of ideology, the subtitle links to the scientific field from which the critical constructionist theory arises: humanities. This is a crucial point in the author's argument. Firstly, the subjects within human sciences operate from the premise that everything in society is a manmade construction. Thus, anthropology, sociology, history, psychology and other sciences deliver a solid message that man constructs himself through processes of phylogenesis and ontogenesis. Secondly, through ideology, current social constructs appear as if they were the only ones possible. If even theoretical concepts can be ideological, the humanities are the point of departure

*E-mail: acfrancisco@daad-alumni.de | ORCID: 0000-0003-1602-8326 
for scientific criticism. For this reason, it is important to be aware of ideology within the concepts of human sciences. Therefore, in human sciences there is a need for conceptual instruments to identify possible theoretical and methodological problems induced by ideology. Lastly, an audience of specialists may be alternatively interested in formulating the concept of ideology, applying these instruments to current ideas in the analyses of particular ideologies.

In the first chapter called Revoke ideology, the author re-formulates a basic understanding of a "critical constructionist vocation within the human sciences" (10). Although there might be theoretical perspectives, constructions, and schools which attempt or attempted in many ways to justify power and domination in the field of human sciences, including many philosophies, the characterisation of human sciences continues to comprise a common convergent point: that of a critical constructionist theory. Simultaneously, if the reality can be interpreted as constructed, the reverse is also possible. Once something is constructed, it can be deconstructed.

In addition, construction does not mean that there is a "construction" separate from human action. Nor the opposite, that there is a conspiracy orchestrated by somebody, invested with full power, who has constructed the reality: the "elite", for example. Reality cannot be easily deconstructed. Human sciences have already shown that social facts are random and coercive. Furthermore, the institution of reality is neither purely linguistic nor discursive nor departs from a reality untouchable. As De Sousa claims, "There is nothing human prior to the human being" (30). However, there are attempts to place something pre-human in the human, in order to justify a unidimensionality which competes with the diversity of human life. For example, arguments suggesting that biology can explain what social is. Thus, he argues that the "natural" is never solely natural, as it is always fashioned by human language" (37).

Moving on, he differentiates real from reality in order to clarify that the construction of reality corresponds just to one dimension of what is real, which is much richer than what that reality exhibits. In a word, "the real is the ballast from which reality extracts the elements of which it constructs its structures and configurations" (41). Nevertheless, acting in this way, reality forecloses real elements that must be left "outside" of the reality. On the one hand, the real continues to exist and, therefore, exerting pressure on the reality since it is only a part of the real. On the other hand, the reality tries to exclude the real which threatens its "integrity". The fundamental idea at this point is its application. Violence, prejudice, emerging groups and actions, social changes, psychic suffering, historical movements, etc. are examples of the real/reality process.

Once the relationship between real and reality is defined, the second chapter seeks to present more details regarding the process of the construction of reality. The author articulates a few concepts which have some tradition in 
the field, and can be useful for the construction of the reality factor. One of these concepts is the "symbolic", always in connection with the "imaginary": "The symbolic, relying on the collective imagination (the imaginary), is capable of providing a foundation to that which has none, making it the production matrix of all meanings that legitimize reality, validating reality, justifying its imperatives and injunctions" (69).

The symbolic regulates the social reality. Through the symbolic it is possible that the institutional life of individuals, social groups, cultures and societies reproduce themselves. Institutions such as family give newborns the symbolic structure from which they will see what is right and wrong, good and evil, incited and discouraged. The symbolic, that exists before someone is born, thanks to the human actions which give continuation to it, is the compass of social reproduction. The socially shared symbolic is also an imposition due to its arbitrariness, in the sense that reality is randomly materialised.

In turn, the imaginary gives a unified meaning or an image of integrity to the instituted reality. Given that there are so many traditions about the foundation of societies, as well as common interpretations regarding their origins, there must have been an imaginary foundation which gave them a shared orientation to stabilise their beliefs. To this pivotal institution the name imaginary is given. Additionally, De Sousa suggests that the imaginary does not work without cultural arbitrariness, so social practices work according to social and cultural imaginary conventions. It involves performativity, that is, the capacity that language has to change reality.

In order to understand how human reality is created, De Sousa resorts to archaeologically reconstructing phylogenesis, in the third chapter. Humans developed a novel way to live according to positive feedback. In short, in "its current form, the human being evolved during the Pleistocene Era. Scientists estimate that the group, Archaic Homo sapiens, evolved between 400,000 and 250,000 years ago, having migrated out of Africa, where it originated some 50,000-100,000 years ago" (101). Nevertheless, this evolution came from 5 to 7 million years ago, at the beginning of a separation from the former primates. To clarify, the primates from today differ phylogenetically from the primates of that time. The same reasoning is valid for us and our ancestors.

Thus, the more our ancestors created, over time, a novel kind of evolution, the more it has become clear that culture is a central phenomenon of social construction. So, what was determined in the past with sociocultural constructions defines what humans are today. Therefore, it defines how they have constructed their own reality up to now. De Sousa criticises the attempt to attribute a "nature" to the "human". In addition, his criticism reaches those who acknowledge that human sciences ought to implement a dialogue with this "natural" perspective. The author states: "Clearly, what is natural nature in the other species, in the human being is learned, acquired and, constructed 
by humans themselves" (108). In this debate's context, De Sousa stands against the idea that there is an innate language settling of the human being, even structurally. Without an institutional apparatus or social groups and units such as family or cultural practices, the newborn would not be able to incorporate the linguistic order of the societies by itself.

Despite this consolidated constructionist thought, a supposed fixed "human" nature relying on biology is making a strong comeback, as if the social phenomena were caused by biological variables. De Sousa considers this turning point an ideological movement that attempts to "restore" forms of oppression from which the human ought to be freed. Actually, to defend human "nature" in the sense that biology ultimately defines the human, without considering social, psychological, cultural, historical or philosophical factors, is to ignore that this defence can produce domination and prejudices. A meaningful example is the human "brain". It is necessary to qualify what the human brain is. Surely, the human brain today differs from the brain of the first humans. In sum, the attempt to localise the social within the brain is an ideology, which has its homophobic variant in the pseudoscience that postulates a biology of the desire.

Then what is ideology? The fourth chapter addresses this question. The concept of ideology is of particular importance to a critical constructionist theory that intends to apprehend why a random reality dominates social life and other realities do not. On the one hand, ideology leads many authors to ignore the issue of ideology. On the other hand, ignorance motivated by ideology has been denounced by many other authors. Additionally, the polyphony of the term "ideology" confuses the terminological use of the concept. Hence, De Sousa proposes 4 categories of non-critical meanings of ideology and suggests abandoning them; ideology is not: 1) the defence of a moral cause; 2) the invisible domination of a single social class; 3) false ideas of reality; and 4) synonymous with thought or outlook or mindset or even worldview. Ideology does not have a cause, although it serves domination, but not of a single class. Furthermore, it has nothing to do with the criteria of truth; it is not false, it simply justifies domination over social systems as a whole. Lastly, ideology differs greatly from ideas because there are ideas which are not ideological, like critical ideas.

Ideology depends substantially on the imaginary and the symbolic. The imaginary assures the ideology of the power of a kind of legitimisation with respect to the unified meaning of social reality, including the arbitrary meaning of the words of a language, up to the belief that society represents an indissoluble and indivisible unity. Since it would be either an indestructible meaning of a word or a perfect unity, the ideological belief could not be contested. Besides, the symbolic gives power to the words, practices, uses, customs, rituals, myths and differences because it concerns how the world is signified. 
Ideology can be analysed from the spectrum of both social representations and discourses. Both themes have been managed by human sciences in order to clarify how societies can reproduce themselves, which is also a topic of subjectivities. Social representations as well as discourses, being symbolic, can involve ideologies, so that one can call them ideological representations or ideological discourses. What societies produce as representations or discourses, in order to both give life to social practices with rituals and to invest power upon individuals with classifications and qualifications, are of interest to the studies about ideology. The justification of such rituals or classifications as necessary processes is the issue presented by the criticism that claims they are social constructions which can be modified.

Therefore, when the ideological world involves individuals there is a critical alternative: to start believing in other possibilities of action. In sum, that happens as follows. One should believe that the reality built around him or herself is not as necessary as is supposed. One can change it. This simple gesture opens the doors to the perception of ideology. By acting this way, one is acting individually and collectively against suffering. However, this is a daily struggle because ideology is like the water invading a leaky boat, which is our lives navigating through unknown oceans. To sum up, the last chapter presents a beautiful picture of a constructionist world. The author recalls the discovery of the sunset on Mars. There, the phenomenon is blue. This exemplar image shows us that our world is a construction that can be critically deconstructed. Our sunset can also be blue. 